\title{
Anthracycline-Induced Cardiotoxicity: Cardiac Monitoring by Continuous Wave-Doppler Ultrasound Cardiac Output Monitoring and Correlation to Echocardiography
}

\author{
Sandra Geiger ${ }^{a *}$ Hans Joachim Stemmler ${ }^{a}$ Patricia Suhl ${ }^{a}$ Petra Stieber $^{c}$ Veronika Lange $^{a}$ \\ Dorothee Baur $^{\mathrm{a}} \quad$ Andreas Hausmann $^{\mathrm{a}}$ Johanna Tischer ${ }^{\mathrm{a}}$ Sophia Horster ${ }^{\mathrm{b} *}$

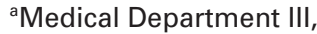

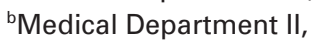 \\ 'Institute of clinical chemistry, Ludwig-Maximilians University of Munich, Germany
}

Keywords

Cardiotoxicity · Anthracyclines - CW-Doppler · USCOM . Ultrasound · NT-pro-BNP · hs-Troponin T

\section{Summary}

Background: Anthracyclines are agents with a wellknown cardiotoxicity. The study sought to evaluate the hemodynamic response to an anthracycline using realtime continuous-wave (CW)-Doppler ultrasound cardiac output monitoring (USCOM) and echocardiography in combination with serum biomarkers. Methods: 50 patients (26 male, 24 female, median age 59 years) suffering from various types of cancer received an anthracycline-based regimen. Patients' responses were measured at different time points (T0 prior to infusion, T1 $6 \mathrm{~h}$ post infusion, T2 after 1 day, T3 after 7 days, and T4 after 3 months) with CW-Doppler ultrasound (T0-T4) and echocardiography (T1, T4) for hemodynamic parameters such as stroke volume (SV; $\mathrm{SV}_{\text {Uscom }} \mathrm{ml}$ ) and ejection frac-

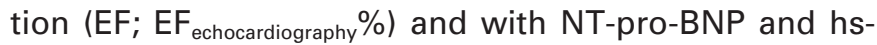
Troponin T (T0-T4). Results: During the 3-month observation period, the relative decrease in the EF determined by echocardiography was $-2.1 \%$ ( $\triangle \mathrm{T} 0-\mathrm{T} 4$, T0 $71 \pm 7.8 \%$, T4 $69.5 \pm 7 \%, p=0.04)$, whereas the decrease in SV observed using CW-Doppler was $-6.5 \% \quad(\Delta \mathrm{T} 0-\mathrm{T} 4, \mathrm{~T} 0$ $54 \pm 19.2 \mathrm{ml}, \mathrm{T} 450.5 \pm 20.6 \mathrm{ml}, \mathrm{p}=0.14)$. The kinetics for serum biomarkers were inversely correlated. Conclusions: Combining real-time CW-Doppler USCOM and serum biomarkers is feasible for monitoring the immediate and chronic hemodynamic changes during an anthracycline-based regimen; the results obtained were comparable to those from echocardiography.

* Sandra Geiger and Sophia Horster contributed equally to this work. $\overline{\text { Schlüsselwörter }}$

Kardiotoxizität · Anthrazykline - CW-Doppler · USCOM . Ultraschall · NT-pro-BNP · hs-Troponin T

\section{Zusammenfassung}

Hintergrund: Anthrazykline sind Substanzen mit einer bekanntermaßen hohen Kardiotoxizität. Diese Studie hatte zum Ziel, die hämodynamischen Veränderungen unter einem Anthrazyklin mittels Continuous-Wave (CW)-Doppler-Ultraschall-Herzauswurf-Monitoring (USCOM) und Echocardiographie sowie mit Serumbiomarkern vergleichend zu untersuchen. Methoden: 50 Patienten (26 Männer, 24 Frauen, medianes Alter 59 Jahre) mit verschiedenen Krebserkrankungen erhielten eine Anthrazyklinbasierte Therapie. An verschiedenen Untersuchungszeitpunkten (T0 vor Infusion, T1 6 h nach Infusion, T2 nach 1 Tag, T3 nach 7 Tagen, und T4 nach 3 Monaten) wurden mittels CW-Doppler Ultraschall (T0-T4) und Echokardiographie (T1, T4) hämodynamische Parameter wie Schlagvolumen (SV Uscom $\mathrm{ml}$ ) und Ejektionsfraktion $\left(\mathrm{EF}_{\text {Echokardiographie }} \%\right)$ sowie Kinetiken von NT-pro-BNP und hs-Troponin T erfasst (T0-T4). Ergebnisse: Während der 3-monatigen Beobachtungszeit betrug der relative Abfall der EF in der Echokardiographie -2,1\% ( $\triangle \mathrm{T} 0-\mathrm{T} 4, \mathrm{~T} 071$ $\pm 7,8 \%$, T4 $69,5 \pm 7 \%, p=0,04)$ wohingegen das mit USCOM bestimmte SV CW-Doppler um $-6,5 \%$ fiel $(\Delta \mathrm{T} 0$ T4, T0 $54 \pm 19,2 \mathrm{ml}, \mathrm{T} 450,5 \pm 20,6 \mathrm{ml}, \mathrm{p}=0,14)$. Eine inverse Korrelation wurde bei der Kinetik der Biomarker beobachtet. Schlussfolgerung: Mit dem CW-Dopplerbasierten USCOM-Verfahren sowie mit Biomarkern lassen sich die akuten und chronischen Veränderungen der Hämodynamik unter einer Anthrazyklin-haltigen Therapie erfassen. Die Ergebnisse sind vergleichbar mit denen der Echokardiographie.

\section{KARGER}

Fax +497614520714

Information@Karger.de

www.karger.com

\section{(c) 2012 S. Karger GmbH, Freiburg}

0378-584X/12/0355-0241\$38.00/0

Accessible online at:

www.karger.com/onk
PD Dr. Hans-Joachim Stemmler

Medical Department III,

Ludwig Maximilians University of Munich, Campus Grosshadern,

Marchioninistr. 15, 81377 Munich, Germany

Tel: +49 89 7095-6017, Fax: -8897

Joachim.Stemmler@med.uni-muenchen.de 


\section{Introduction}

Cytostatic antibiotics of the anthracycline class are chemotherapeutics that are notorious for causing cardiac side effects [1]. Since these novel cancer therapies have improved the long-term survival of patients with malignancies, the importance of their adverse early- and particularly late-onset cardiovascular effects is increasing.

Cardiac events may include symptomatic or asymptomatic blood pressure changes, thrombosis, electrocardiographic changes, arrhythmias, myo-pericarditis, myocardial infarction, cardiomyopathy, cardiac failure (especially left ventricular failure) and congestive heart failure [2]. These may occur within days or weeks after treatment, or sometimes within months or years after termination of chemotherapy. Cardiac damage caused by anthracyclines cannot be attributed to their anti-cancer mechanisms. As the heart is a post-mitotic organ, the only mechanism of adaptation and/or repair is hypertrophy of the remaining myocardium $[3,4]$.

The intention of routine cardiac monitoring during a potentially cardiotoxic chemotherapy regimen is the early detection of restricted cardiac function and, as a consequence, a dose reduction or termination of cardiotoxic treatments. The most specific method for diagnosing myocardial changes during treatment with anthracyclines is endomyocardial biopsy $[3,5,6]$. However, there are non-invasive methods of cardiac monitoring that are more established in clinical routine, such as radionuclide ventriculography and echocardiography. The latter is recommended by the ACC (American College of Cardiology), the AHA (American Heart Association) and the ASE (American Society of Echocardiography) for cardiac monitoring of patients receiving anthracyclines [7, 8].

Atrial natriuretic peptide (ANP) and brain natriuretic peptide (BNP) are important serological parameters for diagnosis, prognosis and response to treatment in patients with acute or chronic heart failure [9-14]. ANP and BNP are cleaved from the C-terminal end of their pro-hormones pro-BNP/pro-ANP and are released into the circulation together with the corresponding $\mathrm{N}$-terminal fragment (N-terminal pro-BNP/NT-pro-BNP, N-terminal pro-ANP/NT-pro-ANP). In heart failure, ANP and BNP release is correlated to the ventricular filling pressure. The plasma concentrations increase during clinical symptomatic or asymptomatic systolic or diastolic dysfunction [16].

Cardiac troponins are proteins with 3 subunits: troponin $\mathrm{T}$ (cTnT), troponin I (cTnI) and troponin C. Cardinale et al. showed that, during treatment with chemotherapy, elevated levels of troponin are associated with a decrease of left ventricular (LV) ejection fraction (EF). In contrast, patients with no elevation of troponin levels during chemotherapy may show a transient reduction of LVEF, which returns to baseline during the long-term follow-up [17-20]. cTnI is a specific and sensitive marker for myocardial damage and can be suggestive for the extent of left ventricular dysfunction in an early stage of therapy [21, 22].
Ultrasound cardiac output monitoring (USCOM; USCOM Pty Ltd, Sydney, Australia) is a non-invasive hemodynamic monitoring system based on continuous-wave $(\mathrm{CW})$ Doppler principle with a transportable touch-screen monitor and 2.2$\mathrm{MHz}$ ultrasound probe. Knobloch and co-workers have shown that combining real-time CW-Doppler ultrasound and serum biomarkers is a feasible method for monitoring the hemodynamic changes to cardiotoxic agents like the anthracyclines or trastuzumab [23, 24].

The aim of our pilot study was to evaluate the hemodynamic response to the anthracyclines with real-time $\mathrm{CW}$ Doppler USCOM and echocardiography in combination with serum biomarker kinetics over a period of 3 months.

\section{Patients and Methods}

\section{Patients}

Fifty patients from the Ludwig-Maximilians University hospital, Munich, Germany were enrolled prospectively into this pilot study. The study protocol was approved by the institutional ethics committee. Informed consent was given by the patient prior to study entry. Data were evaluated descriptively.

Patients receiving a first-line anthracycline (and/or mitoxantrone) -based regimen for hematological malignancies or a solid tumor were eligible. Patients were required to have a Karnofsky Performance Status (KPS) of $\geq 70 \%$ and to be between 18 and 65 years old. Patients who had a positive history of coronary heart disease with cardiac dysfunction (> NYHA I), or an impaired LVEF were not eligible; cardiac EF by echocardiography had to be normal (EF 50\%) prior to study entry. Patients were examined using echocardiography and USCOM at the following time points: Prior to the first anthracycline dose (T0), $6 \mathrm{~h}$ post infusion (T1), after 1 day (T2), after 7 days (T3), and after 3 months (T4), with CW-Doppler ultrasound (T0-T4) and echocardiography (only 2 measurements on $\mathrm{T} 1, \mathrm{~T} 4)$.

The evaluation of hemodynamic parameters included heart rate (HR), stroke volume $(\mathrm{SV}$, by USCOM), cardiac output $(\mathrm{CO} ; \mathrm{CO}=\mathrm{HR} \times \mathrm{SV})$, and EF (by echocardiography). Serum biomarkers NT-pro-BNP and hs-Troponin T were determined at all time points (T0-T4). Drug administration, KPS, and toxicity or adverse events were recorded during the study period.

\section{USCOM}

The USCOM device provides a non-invasive bedside method to evaluate $\mathrm{CO}$ based on CW-Doppler ultrasound. After starting the USCOM device and before typing in the patients data (e.g. height, weight and gender), the left-sided transaortic $\left(\mathrm{CO}_{\text {US-A }}\right)$ or right-sided transpulmonary access $\left(\mathrm{CO}_{\text {Us-P }}\right)$ has to be chosen. The flow profile is obtained using a $2.2-\mathrm{MHz}$ transducer placed on the chest in either the left parasternal position to measure transpulmonary blood flow (right-sided access, 3rd to 5th parasternal intercostal space) or the suprasternal position to measure transaortic blood flow (left-sided access, suprasternal notch). The Doppler flow curve with maximal blood flow is recorded, which is characterized by a sharp, well-defined waveform with the clearest audible sound. The flow profile is displayed as a time-velocity curve on the monitor (VTI = velocity time integral). The device calculates $\mathrm{CO}$ as the product of $\mathrm{SV}$ and $\mathrm{HR}$, where the SV is the product of the VTI and the cross-sectional area of the chosen valve (CSA). The chosen-valve CSA is given by the USCOM internal algorithm based on the typed-in patient data (height and gender).

Measurements made with the USCOM were taken while patients were hemodynamically stable (horizontal or sitting position). To exclude 
inter-individual observer variability, all measurements by USCOM were undertaken by the same investigator.

Validation and reliability studies for USCOM have already been carried out in intensive care studies against invasive thermodilution (pulmonary artery catheter, and/or pulse-induced contour $\mathrm{CO}$ ) with proven high correlation and limits of agreement according to Bland-Altman analysis [25-27].

\section{Results}

\section{Patient Characteristics}

Fifty patients (26 male, 24 female) with a median age of 59 years and a median KPS of $100 \%$ were included in the trial. Of the patients, 18 had a history of hypertension (36\%), and 1 had a history of asymptomatic cardiac insufficiency (NYHA stage I, 2\%). Patients were suffering from different types of cancer: 22 with lymphomas (44\%), 17 with soft-tissue

Table 1. Baseline characteristics

\begin{tabular}{llrr}
\hline & Median (range) & $\mathrm{n}$ & $\%$ \\
\hline Gender & & 26 & 52 \\
$\quad$ Male & & 24 & 48 \\
$\quad$ Female & 59 & & \\
Age & 100 & & \\
KPS & & 18 & 36 \\
Pre-existing cardiovascular disease & & 2 \\
$\quad$ Hypertension & & & \\
$\quad$ Heart insufficiency (NYHA I) & & 22 & 44 \\
Cancer type & & 17 & 34 \\
$\quad$ Lymphoma & & 18 \\
$\quad$ Sarcoma & & 2 & 4 \\
$\quad$ AML & & & \\
$\quad$ Solid tumor & & 40 & 80 \\
Anthracycline-based treatment & & 1 & 2 \\
(cumulative dose at T4), mg/m ${ }^{2}$ & $200(50-450)$ & 40 \\
$\quad$ Doxorubicin & 175 & 1 & 2 \\
$\quad$ Liposomal doxorubicin & 120 & 2 & 4 \\
$\quad$ Liposomal daunorubicin & $45(40-50)$ & 12 \\
$\quad$ Mitoxantrone & $40(30-50)+180$ & 6 & \\
$\quad$ Mitoxantrone + daunorubicin & & & \\
\hline
\end{tabular}

KPS = Karnofsky-Performance Status; AML = acute myeloid leukemia; NYHA = New York Heart Association. sarcomas (34\%), 9 with acute myeloid leukemias (18\%), and 2 with solid tumors (4\%).

All patients received a first-line anthracycline-containing regimen for the malignant disease. The majority $(n=40,80 \%)$ received doxorubicin at a median dose of $200 \mathrm{mg} / \mathrm{m}^{2}(50$ $450 \mathrm{mg} / \mathrm{m}^{2}$ ). 8 patients $(16 \%)$ received mitoxantrone (which has a structural affinity to the anthracyclines), of whom 6 $(12 \%)$ additionally received the anthracycline daunorubicin. The median cumulative doses were calculated at T4 (after 3 months). Detailed information is given in table 1 .

\section{Hemodynamic Parameters}

The initial value of the EF determined by echocardiography was $71 \pm 7.8 \%$ (T0). After 3 months (T4) the EF decreased to $69.5 \pm 7 \%$ resulting in a relative decrease of $-2.1 \%(\Delta \mathrm{T} 0-\mathrm{T} 4$, $\mathrm{p}=0.04)$. The corresponding values of the SV using $\mathrm{CW}$ Doppler ultrasound were $54 \pm 19.2 \mathrm{ml}$ (T0), and $50.5 \pm 20.6 \mathrm{ml}$ (T4). The relative decrease of SV by CW-Doppler ultrasound was $-6.5 \%(\Delta \mathrm{T} 0-\mathrm{T} 4, \mathrm{p}=0.14)$. A summary of all parameters and values is given in table 2 .

None of the patients developed symptoms for cardiac failure during the study period. Among the whole study population, 11 patients $(22 \%)$ developed a clinically significant decrease of $>10 \%$ in EF by echocardiography during the study interval (median EF $\Delta_{\mathrm{T} 0-\mathrm{T} 4}-14.1 \%, \mathrm{p}<0.001$ ). Except for one patient (technical fault with the USCOM device), all of those patients showed a corresponding decrease of the SV by USCOM (median SV $\Delta_{\mathrm{T} 0-\mathrm{T} 4}-16.8 \%, \mathrm{p}=0.03$ ) (fig. 1).

\section{Kinetics of Hemodynamic Parameters and Serum Biomarkers} During the observation period an increase of serum biomarkers was observed. The relative increase of NT-pro-BNP was $+28.9 \%, \Delta \mathrm{T} 0-\mathrm{T} 4$ (T0 $229.2 \pm 886.1 \mathrm{pg} / \mathrm{ml}, \mathrm{T} 4295.4 \pm 1161 \mathrm{pg} /$ $\mathrm{ml}, \mathrm{p}=0.04)$. The corresponding values for hs-Troponin $\mathrm{T}$ levels were $+51.9 \%, \Delta \mathrm{T} 0-\mathrm{T} 4(\mathrm{~T} 07.7 \pm 11.5 \mathrm{pg} / \mathrm{ml}$, T4 $11.7 \pm$ $20.5 \mathrm{pg} / \mathrm{ml}, \mathrm{p}=0.001$ ) (table 2).

Comparing the kinetics of biomarkers and hemodynamic parameters of 'non-high-risk' patients to those of 'high-risk' patients (as defined above; EF decreases by echocardiography $>10 \%, \Delta \mathrm{T} 0-\mathrm{T} 4$ ), two striking differences were seen (fig. 2a, b): - SV by USCOM decreased by $1 \mathrm{ml}(\Delta \mathrm{T} 0-\mathrm{T} 4)$ in 'low-risk' patients and by $10.5 \mathrm{ml}(\Delta \mathrm{T} 0-\mathrm{T} 4)$ in 'high-risk' patients.

Table 2. Medians ( \pm SD) of parameters of echocardiography, USCOM and serum biomarkers during the study period (T0-T4)

\begin{tabular}{|c|c|c|c|c|c|c|c|}
\hline & T0 & $\mathrm{T} 1$ & $\mathrm{~T} 2$ & $\mathrm{~T} 3$ & $\mathrm{~T} 4$ & $\Delta \mathrm{T} 0-\mathrm{T} 4, \%$ & $\mathrm{p}^{\mathrm{a}}$ \\
\hline \multicolumn{8}{|l|}{ Echocardiography } \\
\hline $\mathrm{EF} \pm \mathrm{SD}, \%$ & $71 \pm 7.8$ & - & - & - & $69.5 \pm 6.95$ & -2.1 & 0.04 \\
\hline \multicolumn{8}{|l|}{ USCOM } \\
\hline $\mathrm{SV} \pm \mathrm{SD}, \mathrm{ml}$ & $54 \pm 19.2$ & $62.5 \pm 23.4$ & $61.0 \pm 20.3$ & $54.0 \pm 22.5$ & $50.5 \pm 20.6$ & -6.5 & 0.14 \\
\hline $\mathrm{HR} \pm \mathrm{SD}, \mathrm{bpm}$ & $73 \pm 14.1$ & $74.5 \pm 18.3$ & $74 \pm 18.5$ & $76 \pm 23.8$ & $79.5 \pm 13.7$ & +8.9 & 0.02 \\
\hline $\mathrm{CO} \pm \mathrm{SD}, 1 / \mathrm{min}$ & $4.2 \pm 1.5$ & $4.7 \pm 2.0$ & $4.2 \pm 1.8$ & $4.3 \pm 1.8$ & $4.35 \pm 1.5$ & +3.6 & 0.46 \\
\hline NT-pro-BNP $\pm \mathrm{SD}, \mathrm{pg} / \mathrm{ml}$ & $229 \pm 886$ & $388 \pm 1443$ & $418 \pm 1866$ & $307 \pm 1368$ & $295.4 \pm 1161$ & +28.9 & 0.04 \\
\hline hs-Troponin $\mathrm{T} \pm \mathrm{SD}, \mathrm{pg} / \mathrm{ml}$ & $7.7 \pm 11.5$ & $7.1 \pm 10.6$ & $8.9 \pm 11$ & $8.9 \pm 13$ & $11.7 \pm 20.5$ & +51.9 & 0.001 \\
\hline
\end{tabular}

$\mathrm{EF}$ = ejection fraction; $\mathrm{SD}=$ standard deviation; $\mathrm{SV}=$ stroke volume; $\mathrm{HR}=$ heart rate; $\mathrm{CO}=$ cardiac output; ${ }^{\mathrm{t}}$-test. 
- NT-pro-BNP levels in 'high-risk' patients increased by $254 \%(\Delta \mathrm{T} 0-\mathrm{T} 2)$ within the first week compared to a more moderate increase of $185 \%(\Delta \mathrm{T} 0-\mathrm{T} 2)$ within in the 'lowrisk' patients $(\mathrm{p}=0.04)$.

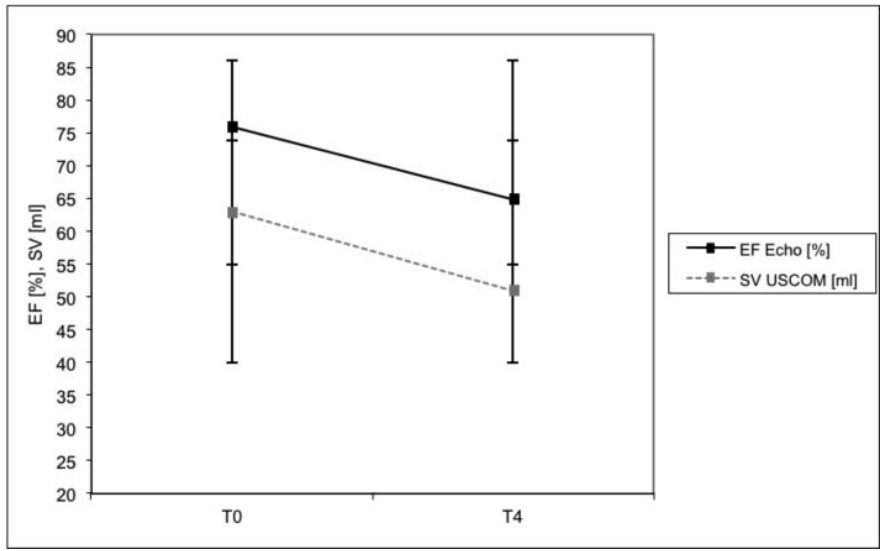

Fig. 1. Patients with an EF decrease of $>10 \%(\Delta \mathrm{T} 0-\mathrm{T} 4)$ by echocardiography $\left(\mathrm{n}=11\right.$, median $\left.\mathrm{EF} \Delta_{\mathrm{T} 0-\mathrm{T} 4}-14.1 \%, \mathrm{p}<0.001\right)$; correlation to SV measurements by USCOM $(\Delta \mathrm{T} 0-\mathrm{T} 4)$ within this subgroup $(\mathrm{n}=10$, median SV $\left.\Delta_{\mathrm{T} 0-\mathrm{T} 4}-16.8 \%, \mathrm{p}=0.03\right)$.
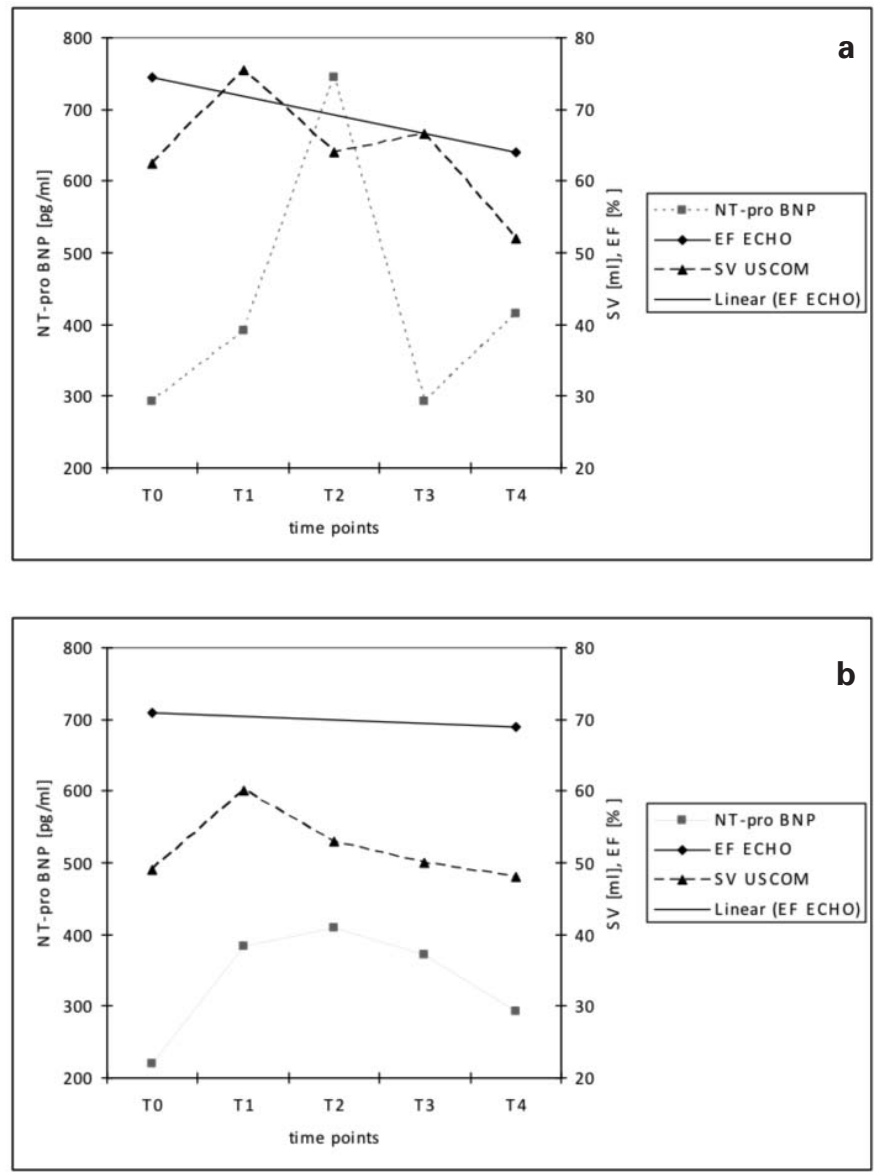

Fig. 2. Median of serum NT-pro-BNP kinetic and $\mathrm{SV}_{\mathrm{Uscom}}(\mathrm{T} 0-\mathrm{T} 4)$ and $\mathrm{EF}_{\text {echocardiography }}(\mathrm{T} 0, \mathrm{~T} 4)$ in, $\mathbf{a}$ high-risk patients (EF decrease $>10 \% \Delta \mathrm{T} 0$ T4), b non-high-risk patients.

\section{Discussion}

With the rapidly increasing arsenal of anti-tumor agents, the myocardial surveillance of patients who receive a potentially cardiotoxic agent is currently gaining in importance. The intention of routine cardiac monitoring is the early detection of restricted cardiac function, which would necessitate dose reduction or interruption (and/or application of cardioprotectants).

Cardiac function has to be monitored for years after anticancer treatment because of the possibility of a late-onset cardiotoxicity [28, 29]. Echocardiography is widely established, generally recommended and must be called the gold standard in clinical routine $[7,8]$. Until now, all methods of myocardial monitoring and the recommendations have been validated solely for the anthracycline- and trastuzumab-induced cardiac damage.

USCOM is a non-invasive CO monitor based on the transthoracic measurement of Doppler flow velocity over the aortic and pulmonary outflow tract. It is easy to operate, and hemodynamic parameters are displayed 'beat by beat'. Following a short booting time the device can be used immediately. Moreover, the technique is reported to be easy to use after a short teaching period [30, 31]. Validation and reliability studies have been carried out in intensive care studies against invasive hemodynamic monitoring devices such as pulmonary artery catheter and other thermodilution techniques with proven high correlation [25-27].

Knobloch and co-workers used CW-Doppler USCOM and NT-pro-BNP measurements for monitoring the hemodynamic response in patients receiving an anthracycline- or trastuzumab-based regimen for breast cancer [23, 24]. In contrast to our study, their measurements were restricted to a short interval comprising the time prior to infusion until $10 \mathrm{~min}$ after infusion [23, 24]. In both studies, they demonstrated an immediate up-regulation of SV (and consecutively $\mathrm{CO}$ ), suggesting that a compensatory hemodynamic mechanism might be involved [23, 24]. A volume effect could be ruled out since Knobloch et al. applied liposomal doxorubicin (equal infusion volume) to a comparative cohort in whom changes of SV or $\mathrm{CO}$ were not detected.

The finding of an increased SV (and CO) immediately after infusion was also seen in our study. Overall, SV increased from $54 \pm 19.2 \mathrm{ml}$ (T0) to $62.5 \pm 23.4 \mathrm{ml}$ (T1) and CO from $4.2 \pm 1.5 \mathrm{l} / \mathrm{min}(\mathrm{T} 0)$ to $4.7 \pm 2.0 \mathrm{l} / \mathrm{min}(\mathrm{T} 1)$, which was not related to an increasing heart rate (T0 $73 \pm 14.1 \mathrm{bpm}, \mathrm{T} 1$ $74.5 \pm 18.3 \mathrm{bpm})$.

Gustafsson and co-workers investigated the diagnostic and prognostic performance of NT-pro-BNP in primary care patients with suspected congestive heart failure. In summary, the mortality rate was higher in patients with NT-pro-BNP levels $>125 \mathrm{pg} / \mathrm{ml}$ than in patients with normal values $(p<0.002)$. This difference persisted after controlling for age, gender, and LVEF [16]. Knobloch et al. observed an up-regu- 
lation of SV that was more pronounced in patients with high NT-pro-BNP levels $(>125 \mathrm{pg} / \mathrm{ml})$ prior to the anthracycline infusion. They concluded that this finding might reflect a disturbed cardiac function even at baseline [23, 24].

In contrast to these reported trials, our study focused on the kinetics of hemodynamic parameters and biomarkers over a period of 3 months. Moreover, all recruited patients were chemo-naïve and had received a first-line anthracyclinecontaining regimen. The correlation of USCOM to the gold standard 'echocardiography' was evident in our trial. All patients (except 1 due to a technical fault of the USCOM device) who had developed a decrease in the EF detected by echocardiography during the study interval showed a corresponding decrease of the SV detected by USCOM. In addition to a more long-term effect, from the analysis of the kinetics of serum NT-pro-BNP levels in our patients, it can be hypothesized that there is also an 'immediate effect' of the anthracyclines. Not only was the increase of serum biomarkers inversely correlated to the EF by echocardiography and SV by USCOM, there was also an obvious striking increase of NT-pro-BNP levels following the anthracycline infusion, which was pronounced in 'high-risk' patients, defined as patients whose EF by echocardiography decreased $>10 \%$ during the observation period $(\Delta \mathrm{T} 0-\mathrm{T} 4)$. The SV by USCOM decreased by $10.5 \mathrm{ml}(\Delta \mathrm{T} 0-\mathrm{T} 4)$, which was significantly different to 'low-risk patients' whose SV by USCOM decreased by no more than $1 \mathrm{ml}$ during the study period $(\Delta \mathrm{T} 0-\mathrm{T} 4)$. Moreover, NT-pro-BNP levels in 'high-risk' patients increased by $254 \%(\Delta \mathrm{T} 0-\mathrm{T} 2)$ within the first week compared to a more moderate increase of $185 \%(\Delta \mathrm{T} 0-\mathrm{T} 2)$ in the 'low-risk' patients $(\mathrm{p}=0.04)$. It may be possible that 'high-risk' patients could be identified by the early increase of NT-pro-BNP within the first week of treatment.

Despite some striking observations, the results and conclusions of our study are hampered by several factors:

1. The present study was initiated as a pilot study with the aim of evaluating the hemodynamic response to the anthracyclines with real-time CW-Doppler USCOM, echocardiography and serum biomarkers over a period of 3 months. It is not possible to draw any final conclusions from such a small study. Nevertheless, the study provides data justifying further clinical studies evaluating USCOM in hematology and oncology.
2. None of the patients became symptomatic for cardiac failure during the study period. Despite some significant changes in SV, EF and serum biomarkers, these observations were made in an asymptomatic patient population over a short interval of only 3 months. Moreover, the cumulative anthracycline doses were relatively low.

3. The accuracy of the USCOM depends on a good flow signal. Moreover, USCOM, like echocardiography, is an ultrasound-based device. For USCOM it has been shown that personnel can be trained to obtain reliable SV and $\mathrm{CO}$ estimations over the course of 20 patient assessments [30].

4. Biomarkers such as NT-pro-BNP are influenced by age, gender, renal function and co-medication with ACE inhibitors, $\beta$-blockers and diuretics. To our best knowledge, none of the patients included in the study had received such medications, and all had a serum creatinine level within the normal range.

In summary, the major findings of this study were: None of the patients became symptomatic for cardiac failure during the study period. A clinically significant decrease in the EF by echocardiography was mostly paralleled by a corresponding decrease in the SV by USCOM. The increase in levels of serum biomarkers was inversely correlated to EF by echocardiography and SV by USCOM, indicating a negative impact on myocardial function of the applied chemotherapy. Clearly, USCOM does not replace standard methods such as echocardiography in the cardiac surveillance of patients undergoing an anthracycline-based chemotherapy. But USCOM is attractive in many ways. It is easy to use, and as an ultrasound technique safe, so it can be used repeatedly to measure the trend over time. Moreover, using the USCOM device, the physician will obtain a result in an unbeatable period of time. The role of USCOM is evolving in intensive care medicine. In our opinion this technique deserves closer attention in the cardiac monitoring of cancer patient populations. The present study justifies further clinical studies evaluating USCOM in hematology and oncology.

\section{Disclosure Statement}

The authors declare no conflict of interest.

\section{References}

1 Jain D: Cardiotoxicity of doxorubicin and other anthracycline derivatives. J Nucl Cardiol 2000; 7:5362.

2 Ryberg M, Nielsen D, Skovsgaard T, Hansen J, Jensen BV, Dombernowsky P: Epirubicin cardiotoxicity: An analysis of 469 patients with metastatic breast cancer. J Clin Oncol 1998;16:3502-3508.

3 Meinardi MT, van der Graaf WT, van Veldhuisen DJ, Gietema JA, de Vries EG, Sleijfer DT: Detection of anthracycline-induced cardiotoxicity. Cancer Treat Rev 1999;25:237-247.
4 Elliott P: Pathogenesis of cardiotoxicity induced by anthracyclines. Semin Oncol 2006;33:S2-7.

5 Cooper LT, Baughman KL, Feldman AM, Frustaci A, Jessup M, Kuhl U, Levine GN, Narula J, Starling RC, Towbin J, Virmani R: The role of endomyocardial biopsy in the management of cardiovascular disease: A scientific statement from the American Heart Association, the American College of Cardiology, and the European Society of Cardiology. Endorsed by the Heart Failure Society of America and the Heart Failure Associa- tion of the European Society of Cardiology. J Am Coll Cardiol 2007;50:1914-1931.

6 Cooper LT, Baughman KL, Feldman AM, Frustaci A, Jessup M, Kuhl U, Levine GN Narula J, Starling RC, Towbin J, Virmani R: The role of endomyocardial biopsy in the management of cardiovascular disease: A scientific statement from the american heart association, the American College of Cardiology, and the European Ssociety of Cardiology. Circulation 2007;116:2216-2233. 
7 Cheitlin MD, Alpert JS, Armstrong WF, Aurigemma GP, Beller GA, Bierman FZ, Davidson TW Davis JL, Douglas PS, Gillam LD: ACC/AHA guidelines for the clinical application of echocardiography. A report of the American College of Cardiology/American Heart Association task force on practice guidelines (committee on clinical application of echocardiography). Developed in collaboration with the American Society of Echocardiography. Circulation 1997;95:1686-1744.

8 Cheitlin MD, Armstrong WF, Aurigemma GP, Beller GA, Bierman FZ, Davis JL, Douglas PS Faxon DP, Gillam LD, Kimball TR, Kussmaul WG, Pearlman AS, Philbrick JT, Rakowski H, Thys DM, Antman EM, Smith SC, Jr., Alpert JS, Gregoratos G, Anderson JL, Hiratzka LF, Hunt SA, Fuster V, Jacobs AK, Gibbons RJ, Russell RO: ACC/AHA ASE 2003 guideline update for the clinical application of echocardiography: Summary article: A report of the American College of Cardiology/American Heart Association task force on practice guidelines (ACC/AHA/ASE committee to update the 1997 guidelines for the clinical application of echocardiography). Circulation 2003;108:11461162

9 Urek R, Cubrilo-Turek M: [Natriuretic peptides in clinical practice]. Acta Med Croatica 2008;62:53-

10 Mueller C: Comparison of the diagnostic accuracy of BNP and NT-proBNP in acute and chronic heart failure. Clin Chem 2007;53:1719-1720; author reply 1720-1711.

11 Mueller C, Breidthardt T, Laule-Kilian K, Christ M, Perruchoud AP: The integration of BNP and NT-proBNP into clinical medicine. Swiss Med Wkly 2007;137:4-12.

12 Mueller T, Gegenhuber A, Poelz W, Haltmayer M Diagnostic accuracy of B type natriuretic peptide and amino terminal proBNP in the emergency diagnosis of heart failure. Heart 2005;91:606-612.

13 Kinnunen P, Vuolteenaho O, Ruskoaho H: Mechanisms of atrial and brain natriuretic peptide release from rat ventricular myocardium: Effect of stretching. Endocrinology 1993;132:1961-1970.

14 Rademaker MT, Richards AM: Cardiac natriuretic peptides for cardiac health. Clin Sci (Lond) 2005; 108:23-36.
15 Iwanaga Y, Nishi I, Furuichi S, Noguchi T, Sase K, Kihara Y, Goto Y, Nonogi H: B-type natriuretic peptide strongly reflects diastolic wall stress in patients with chronic heart failure: Comparison between systolic and diastolic heart failure. J Am Coll Cardiol 2006;47:742-748.

16 Gustafsson F, Steensgaard-Hansen F, Badskjaer J, Poulsen AH, Corell P, Hildebrandt P: Diagnostic and prognostic performance of $\mathrm{N}$-terminal proBNP in primary care patients with suspected heart failure. J Card Fail 2005;11:S15-20.

17 Cardinale D, Colombo A, Sandri MT, Lamantia G, Colombo N, Civelli M, Martinelli G, Veglia F, Fiorentini C, Cipolla CM: Prevention of high-dose chemotherapy-induced cardiotoxicity in high-risk patients by angiotensin-converting enzyme inhibition. Circulation 2006;114:2474-2481.

18 Cardinale D, Sandri MT, Colombo A, Colombo N, Boeri M, Lamantia G, Civelli M, Peccatori F, Martinelli G, Fiorentini C, Cipolla CM: Prognostic value of troponin I in cardiac risk stratification of cancer patients undergoing high-dose chemotherapy. Circulation 2004;109:2749-2754.

19 Cardinale D, Sandri MT, Martinoni A, Borghini E, Civelli M, Lamantia G, Cinieri S, Martinelli G, Fiorentini C, Cipolla CM: Myocardial injury revealed by plasma troponin I in breast cancer treated with high-dose chemotherapy. Ann Oncol 2002;13:710-715.

20 Cardinale D, Sandri MT, Martinoni A, Tricca A, Civelli M, Lamantia G, Cinieri S, Martinelli G, Cipolla CM, Fiorentini C: Left ventricular dysfunction predicted by early troponin I release after high-dose chemotherapy. J Am Coll Cardiol 2000; 36:517-522.

21 Koh E, Nakamura T, Takahashi H: Troponin-T and brain natriuretic peptide as predictors for adriamycin-induced cardiomyopathy in rats. Circ J 2004;68:163-167.

22 Lipshultz SE, Giantris AL, Lipsitz SR, Kimball Dalton V, Asselin BL, Barr RD, Clavell LA, Hurwitz CA, Moghrabi A, Samson Y, Schorin MA, Gelber RD, Sallan SE, Colan SD: Doxorubicin administration by continuous infusion is not cardioprotective: The Dana-Farber 91-01 acute lymphoblastic leukemia protocol. J Clin Oncol 2002;20: 1677-1682.
23 Knobloch K, Tepe J, Lichtinghagen R, Luck HJ, Vogt PM: Simultaneous hemodynamic and serological cardiotoxicity monitoring during immunotherapy with trastuzumab. Int J Cardiol 2008; 125:113-115.

24 Knobloch K, Tepe J, Rossner D, Lichtinghagen R, Luck HJ, Busch KH, Vogt PM: Combined NT-pro$\mathrm{BNP}$ and CW-doppler ultrasound cardiac output monitoring (USCOM) in epirubicin and liposomal doxorubicin therapy. Int J Cardiol 2008;128:316325.

25 van Lelyveld-Haas LE, van Zanten AR, Borm GF, Tjan DH: Clinical validation of the non-invasive cardiac output monitor USCOM-1a in critically ill patients. Eur J Anaesthesiol 2008;25:917-924.

26 Tan HL, Pinder M, Parsons R, Roberts B, van Heerden PV: Clinical evaluation of uscom ultrasonic cardiac output monitor in cardiac surgical patients in intensive care unit. Br J Anaesth 2005; 94:287-291.

27 Stemmler HJ, Weigert O, Grüner N, Tschöp K, Lange V, Parhofer KG: Non-invasive hemodynamic monitoring in critically ill patients: Experience with the USCOM device. Intensivmed 2007;44:366-371.

28 Goorin AM, Chauvenet AR, Perez-Atayde AR, Cruz J, McKone R, Lipshultz SE: Initial congestive heart failure, six to ten years after doxorubicin chemotherapy for childhood cancer. J Pediatr 1990; 116:144-147.

29 Steinherz LJ, Steinherz PG, Tan CT, Heller G, Murphy ML: Cardiac toxicity 4 to 20 years afte completing anthracycline therapy. JAMA 1991; 266:1672-1677.

30 Dey I, Sprivulis P: Emergency physicians can reliably assess emergency department patient cardiac output using the uscom continuous wave doppler cardiac output monitor. Emerg Med Australas 2005;17:193-199.

31 Knobloch K, Hubrich V, Rohmann P, Lupkemann M, Gerich T, Krettek C, Phillips R: Feasibility of preclinical cardiac output and systemic vascular resistance in hems in thoracic pain--the ultrasonic cardiac output monitor. Air Med J 2006;25:270 275. 